\section{Even More about Torrey Canyon}

THE effect of the Torrey Canyon disaster of March 18 on marine life continues to be studied by biologists. Two teams-one from the Marine Biological Association at Plymouth, and one sponsored by the Ministry of Agriculture, Fisheries and Food-have, since April, been assessing the biological damage below low tide mark in the vicinity of Porthleven and Gunwalloe. The results of their observations are published in the Underwater Association Report for 1966-67.

It is now generally accepted that detergents, highly toxic emulsifying agents, do most of the damage to marine organisms. The data in the report indicate the symptoms of infected animals, and one noticeable feature is the differential vulnerability shown by some species. Among the Decapod Crustacea, the commercially important edible crab, Cancer paganis, and the lobster, Homarus vulgaris, are relatively resistant but become sluggish when seriously affected and crabs may lose their legs. Some molluscs, including the razor shell, Ensis siliqua, are extremely vulnerable and appear to enter a narcotized state before death. Black patches develop on the epidermis of certain echinoderms in weak concentrations of detergent, and in stronger concentrations the animals quickly die and fall into gulleys between rocks. Fish were noticeably absent in areas heavily treated with detergent and very few corpses were seen. The teams also investigated two important habitats-rock with Laminaria forest, and clean sand. Of the two, unhealthy and dead species were more common in the sand habitat: evidence of damage in the rock habitat was only seen for a limited distance offshore and, by the beginning of June, all corpses had disappeared and only healthy ones remained in rather depleted stores stocks.

The cause of the differential vulnerability is unknown. It may be caused by differences in habitat or differences in the feeding habits of the various organisms.

\section{Hazards below Ground}

The Federal Radiation Council in the United States has now set out to provide guidance for the control of radiation hazards in uranium mining-chiefly an enhanced risk of lung cancer. The principal cause of the increased incidence of lung cancer among uranium miners is continued exposure to the radioactive decay products of radon-22. These are polonium-218, lead-214, bismuth-214 and polonium-214. It is known that some of the radon daughters contained in the air breathed by miners are retained in the respiratory system. The development of lung cancer may follow some ten to twenty years later.

The council measures the hazard in working levels, defined as any combination of radon daughters in 1 litre of air that will result in the ultimate emission of $1 \cdot 3 \cdot 10^{-5} \mathrm{MeV}$ of potential $\alpha$-energy. In unventilated underground mines, the concentration of radon daughters has been found to vary from a fraction of a working level to several hundred times the level. Although some degree of risk presumably exists at all levels of exposure, maximum incidence of lung cancer occurs when the cumulative exposure exceeds 1,000 working level months (WLM), when the miners are moderate to heavy smokers, and when they have worked in mines for ten or more years.
A significant reduction in the concentration of radon daughters in the air of underground mines has been achieved since 1960. The simplest control technique is by ventilation with fresh air, although studies have been made on possible procedures that might be used to prevent the diffusion of radon from rock into mine air. Another practice is to limit a miner's occupancy time in relatively high concentrations of radon or its daughter products. Despite the healthier working conditions introduced during the past decade, the council recommends that steps to make improvements should begin immediately and made operational as soon as possible. But the council recognizes that present regulations and technology are inadequate to ensure compliance with its recommendations. It puts its trust in research, development and education of the miner.

\section{Wider Patent Laws}

Delegates from twenty-four countries-Argentina, Australia, Austria, Belgium, Brazil, Canada, Czechoslovakia, Denmark, France, West Germany, India, Italy, Japan, Mexico, Netherlands, Norway, Poland, South Africa, Spain, Sweden, Switzerland, UK, USA, and USSR--were meeting this week in Geneva to discuss the plan for a Patent Co-operation Treaty which has been prepared by the United International Bureaux for the Protection of Intellectual Property (BIRPI). Agreement could imply a big step forward towards a more rational patent law.

Many attempts have been made to do this. The Patent Group of the Union of the Industries of the European Community has already tried to unify the patent system of the Six, but that plan has, for the time being, been shelved. The Council of Europe has the Strasbourg Convention which standardized administration procedure in making a standard application form for all countries. The big problem is, however, to obtain. wider coverage for patents; as things are, applications have to be made to each country separately and this takes much time and expense and even then may not be entirely satisfactory. The meeting in Geneva was to discuss plans for an international centre for patents where a patent application would be forwarded to by a national office. The centre would distribute the patent application to any country nominated by the inventor. How much work this centre would do is one of the topics debated this week. It has been suggested that the centre should issue a report of novelty; an immediate anticipation search should be carried out by the centre or the national patent office but using the same standards, and a certificate of patentability should be issued by the centre after a patentability examination has been carried out by the centre or the national patent office. The certificate would have indicative value only and national offices would be under no obligation to recognize it. The British attitude to these and other proposals should be clarified when the report of the Banks Committee on Patent Reform is published in the middle of next year.

\section{Facing the Food Shortage}

AN international seminar on Change in Agriculture is to be held in September 1968 and is being organized by the University of Reading with the co-operation 